\title{
HUKUM ADAT MELAYU MELINGKAT INGAR SILAT KECAMATAN KAYAN HILIR KABUPATEN SINTANG
}

Sudarto, Anyan, dan Lusila Parida

STKIP Persada Khatulistiwa Sintang

sudarto.niarto@gmail.com, anyanright@gmail.com, dan 30101986LP@gmail.cm

Abstract: PkM is aimed to find out the compilation and sanction of Malay customary law of Ingar Silat Subdistrict of Kayan Hilir Subdistrict Sintang. The stages of implementation methods by way of preparation, implementation of program activities, management of community organizations, partner participation, program evaluation, program reports. The results of this PkM are Adat Pemali, Marriage Law, Indigenous Fighting, Fights / Disputes, Family Law, Customary Inheritance, Wills, Indigenous Grants, Indigenous Paws, Land Disputes, Customary Rights, Indigenous Custom, Kind, Nuba Adat, and Pets.

Keyword: Malay Customary Law, of Village Melingkat

\begin{abstract}
Abstrak: PkM ini bertujuan untuk mengetahui penyusunan dan sanksi hukum adat Melayu Melingkat Ingar Silat Kecamatan Kayan Hilir Kabupaten Sintang. Adapun tahapan metode pelaksanan dengan cara persiapan, pelaksanaan kegiatan program, manajemen organisasi masyarakat, partisipasi mitra, evaluasi program, laporan program. Hasil PkM ini adalah Adat Pemali, Hukum Nikah/Perkawinan, Adat Berdusa, Perkelahian/Pertikaian/Sengketa, Hukum Keluarga, Waris Adat, Wasiat, Hibah Adat, Gadai Secara Adat, Sengketa Tanah, Hak Ulayat, Adat Biasa, Kesupan, Nuba Adat, dan Hewan Peliharaan.

Kata Kunci: Hukum Adat, Melayu Desa Melingkat
\end{abstract}

\section{Pendahuluan}

$$
\text { Masyarakat Melayu }
$$

Melingkat merupakan Melayu asli Ingar

Silat. Kawasan yang juga termasuk dalam daerah Kabupaten Sintang seperti di Kota Sintang, namun di Kota Sintang pengaruh hukum adat mengalami kepudaran seiring dengan perkembangan dan akulturasi antara Masyarakat Hukum Adat Melayu Melingkat Ingar Silat dengan para pendatang dari berbagai latar belakang daerah dan suku. Hal ini berbeda dengan keadaan di Desa Melingkat,
Kecamatan Kayan Hilir, Kabupaten Sintang, Provinsi Kalimantan Barat, dimana mayoritas penduduk desa Melingkat merupakan masyarakat asli Melayu Ingar Silat sehingga pengaruh hukum adat disana masih memiliki pengaruh yang kuat.

Hukum adat adalah hukum tidak tertulis, yang merupakan pedoman bagi sebagian besar orang-orang Indonesia dan dipertahankan dalam pegaulan hidup sehari-hari baik di kota maupun di desa (Bushar Muhammad, 


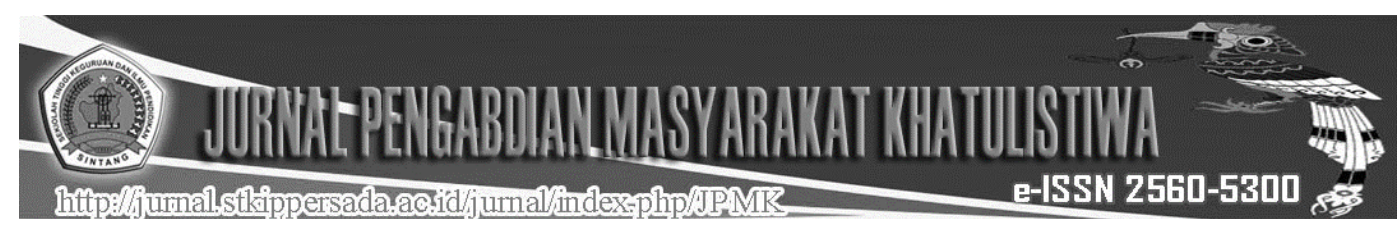

2013: 61-62). Masyarakat hukum adat yang susunannya bersifat teritorial, adalah masyarakat hukum di mana para anggotanya merasa terikat satu sama lain, karena merasa berasal dari daerah yang sama.Ada tiga jenis masyarakat hukum adat yang strukturnya bersifat teritorial, yaitu : masyarakat hukum desa; masyarakat hukum wilayah (persekutuan desa) dan masyarakat hukum sertikat desa (perserikatan desa).

C. Dewi Wulansari (2012: 25) mengatakan bahwa hukum adat adalah istilah untuk menunjukkan hukum yang tidak dikodifikasikan dalam kelangan orang Indonesia asli dan kalangan timur asing (tionghoa, arab dll). Hukum adat senantiasa tumbuh dari suatu kebutuhan hidup yang nyata, cara hidup dan pandangan hidup yang keseluruhannya merupakan kebudayaan masyarakat tempat hukum adat itu berlaku.Hukum pidana adat secara umum berisi mengenai aturan-aturan hukum yang kebanyakan bersifat tidak tertulis namun memiliki akibat hukum bagi siapapun yang melanggar hukum tersebut, didalam wilayah hukum adat tersebut berlaku. Hukum adat masih memiliki pengaruh yang kuat dalam lingkungan Masyarakat Hukum Adat Melayu Melingkat Ingar Silat. Hukum adat yang masih tetap dipegang teguh oleh masyarakat Melayu Melingkat sampai saat ini di antaranya hukum adat menghamili perempuan di luar menikah atau kampang, berzinah, mencuri, membunuh, dan bertengkar.

D. Purba, J., dkk (2009: 20) mengatakan bahwa dalam bukunya yang berjudul "Sejarah Penyebaran dan Pengaruh Budaya Melayu di Kalimantan Barat"dalam salah satu bagian menulis tentang kesultanan Sambas. Tulisan ini menampilkan sejarah awal Sambas, sejak nama ini mulai ditulis hingga sultan-sultan yang berkuasa.Hukumadatadalahmerupakanb agiandarikebudayaanbangsa Indonesia. Olehsebabitu,denganmempelajarihuku madatberartikitatelahmempelajarisebagi andarikebudayaanbangsakita. Orang mencampur-

adukkanantarapengertianadat yang mengandungsanksiyaituhukumadatdeng anpengertianadat yang tidakmengandungsanksiyaitukebiasaans aja.

Devita Irna Purnamasari (2014: 10) mengataka bahwa hukum waris adat adalah sistem kewarisan adat yang secara turun-temurun yang dilakukan oleh masyarakat melayu. Muin Ikram (2007: 2) dalam bukunya SejarahHukum Adat dan Adat Istiadat Kalimantan - Barat, pada bagian Perkawinan Adat Daerah Sambas (Melayu), Lontaan menampilkan 
gambaran tentang adat perkawinan dalam masyarakat Melayu Sambas. Adat yang dideskripsikan di sini meliputi mencari jodoh, perantara, adat menyongsong perkawinan, mandi belulus, balik tikar dan tepung tawar. Meskipun terbatas informasi yang disajikan, tetapi, deskripsi ini membantu memahami bahwa perkawinan merupakan salah satu bahan identitas masyarakat Sambas, bahan yang membuat mereka berbeda dibandingkan Melayu yang lain.

\section{Metode Pelaksanaan}

Kegiatan dilakasanakan pada malam minggu tanggal 10 Oktober 2017 di Desa Melingkat Kecamatan Kayan Hilir Kabupaten Sintang. Adapun tahapan metode pelaksanaan kegiatan diantarany persiapan (sosialisasi, penyusunan, dan evaluasi program), pelaksanaan kegiatan program, Manajemen Organisasi Masyarakat, partisipasi warga, dan laporan.

\section{Hasil PkM}

Hasil PkM di Desa Melingkat terkait "Hukum Adat Melayu Melingkat Kecamatan Kayan Hilir Kabupaten Sintang" adalah sebagai berikut. BAB I SUSUNAN PENGURUS. Susunan Pengurus Adat Istiadat Suku Melayu Desa Melingkat Kecamatan Kayan Hilir, seperti terlampir. BAB II KETENTUAN

UMUM Pasal 1Adat Istiadat adalah kebiasaan perilaku kehidupan manusia secara turun temurun yang diakui kebenarannya dan dijunjung tinggi oleh masyarakat suku melayu yang mayoritasnya umat yang beragama Islam, dan bersamaan dengan hukum syarat berazaskan Al-Qur'an dan Hadisthadistnya dalam lingkungan Kecamatan Kaya Hilir.Pasal 2Untuk menegakkan adat tersebut di dalam hukum adat diberlakukan juga sangsi bagi para pelanggarnya.

Pasal 3Yang berwenang mengurus dalam setiap perkara pelanggaran adalah pimpinan adat suku melayu secara berjenjang ke atas. Pasal 4 Nama denda adat adalah Realyang nilai persatu Realnya Rp. 10.000,(Sepuluh Ribu Rupiah). Pasal 5 Hukum adat ini berlaku untuk setiap peristiwa yang terjadi di wilayah Kecamatan Kayan Hilir bagi suku Melayu. BAB IIIADAT PEMALI

Pasal 6 Pemali (Adat Pelanggar Pantangan): Pemali adalah adat pelanggar pantangan menurut adat atau kecampuran. Menyumpah anak-anak oleh orang tuanya sendiri umpamanya mudah-mudahan kamu ditangkap buaya atau lain sebagainya, bapak dan mamaknya memberikan keras sengkelen kepada anak: ayam 1 ekor 


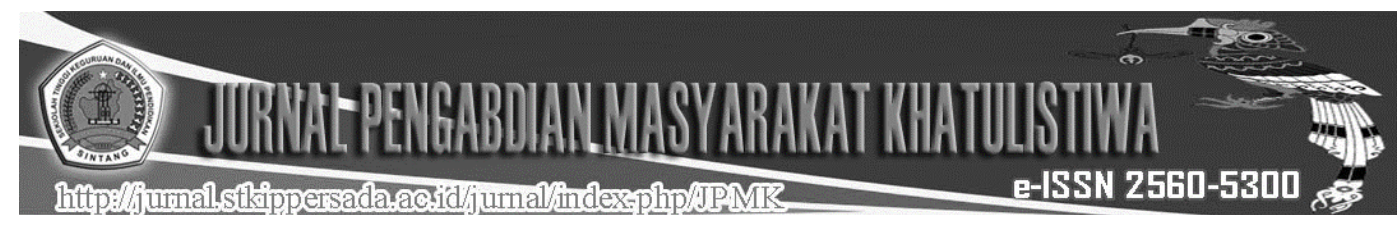

beras 1 gantang dan berupa berisi 1 butik belah juga/dengan pakai selamat dan tulak bala. Kalau menyumpahorang lain kena adat 20 real ditambah keras sengkelan. Adat pemali bermacammacam, umpamanya dia berkelahi melukai seseorang luka ringan atau berat, adat sesuai dengan perbuatan, tetapi dia tetap membayar keras sengkelan ataupun menyumpah mmudah-mudahan kamu mati dibunuh atau lain-lain sebagainya.

\section{BAB IV} NIKAH/PERKAWINAN

7Nikah yaitu HUKUM Pasal mengesahkan/menghalalkan hubungan perkawinan/persetubuhan kedua mempelai laki-laki dan perempuan. Pasal 8 Hukum nikah ada 5 macam: (1) Adanya pengantin laki-laki, (2) Adanya pengantin wanita, (3) Wali, (4) 2 orang saksi, dan (5) Ijab dan Kobul. Dilengkapi dengan mahar/pemberian oleh pengantin laki-laki kepada pengantin perempuan yang berupa uang atau barang sebagai pengakuan istri.

Pasal 9 Proses

pernikahan/perkawinan diawali dengan persyaratan sebagai berikut: (1) Barang siapa yang akan melaksanakan pernikahan/perkawinan sekurangkurangnya telah sampai: (a) Laki-laki telah dewasa, (b) Perempuan telah dewasa, (c) Telah mendapat persetujuan dari orang tua/wali, (d) Telah mendapat ijin tertulis dari Kepala Desa, (e) Telah mendapat petunjuk dari BP4, dan (f) Memenuhi Peraturan Pemerintah Nomor : 1 Tahun 1974 terlampir.

Pasal 10BertunangPenyunset : (a) Seorang laki-laki yang dimmaksud meminang seorang perempuan 1 gadis untuk menjadi istrinya, ia mengutus satu/dua persuruh untuk memenuhi orang tua/wali pihak perempuan yang akan dipinang dengan membawa uang senilai Rp.50.000,- (Lima Puluh Ribu Rupiah) dan (b) Bila lamaran ditolak atau diterimma oleh pihak perempuan harus memberikan jawaban yang tegas, sedangkan uang penyunset dikembalikan (Uang campak uang).

Pasal 11Pembuka Suara /Ikatan Tunang adalah peresmian pertunangan agar diketahui oleh umum bahwa kedua bujang dan dara sudah ada ikatan tunang yang tak sekaligus menyerahkan barang-barang tunangan beserta kata penyerahan barang serta uang adat ikatan pertunangan. Adapun adat pembuka suara/ikatan pertunangan sebagai berikut:Pihak laki-laki harus memenuhi kewajiban sebagai berikut: (a) Uang tunai disesuaikan, (b) Satu helai balak, (c) Satu helai baju kabaya, (d) Satu helai selendang, (e) Alat-alat mandi dan akaca lekan, dan (f) Pesalin kedua orang tua sebelah perempuan 
yaitu: -Pihak laki-laki: 1 sarung, 1 baju, 1 kopiah-Pihak istri: 1 sarung, 1 baju, 1 selendang

$$
\text { Pasal 12Balang Tunang }
$$

Kalau baling tunang dari pihak laki-laki tanpa sebab/kesalahan perempuan barang tidak dikembalikan dari pihak laki-laki membayar adat 20 real kepada pihak perempuan. (2) Kalau baling tunang dari pihak perempuan tanpa sebab/kesalahan dari pihak laki-laki barang dikembalikan dan membayar adat 20 real kepada laiki-laki, begitu pula sebaliknya kalau pihak laki-laki punya kesalahan yang patal yang tidak dapat dimaafkan adat tidak dibayar dan barang tidak dikembalikan andai kata pihak perempuan yang berbuat kesalahan tapi pihak laki-laki tidak mau lagi maka pihak perempuan membayar adat kepihak laki-laki 20 real dan barang dikembalikan.

\section{Pasal 13Perangkat Tunang.} Perangkat tunang adalah seorang lakilaki atau perempuan yang sedang bertunang, kawin dengan lakilaki/perempuan lain maka dikenakan adat sebagai berikut: (1) Laki-laki: Tanda tunang hilang tidak dikemmbalikan pihak perempuan, Membayar adat 1000 Real kepada perempuan, Membayar ketupan orang tua perempuan sebesar 20 real, (2)
Perempuan: Seluruh barang antara dikembalikan, Membayar adat 20 real kepada pihak laki-laki, Membayar adat ketupan orang tua laki-laki 20 real.

\section{Pasal 14Perkawinan}

Meminang adalah kegiatan upacara adat penyerahan barang-barang antara pihak laki-laki kepada pihak perempuan dan adat sebagai berikut: (a) Adat pakaian perempuan yaitu 115 real kalau gadis, (b) Adat pakaian perempuan yaitu 80 real kalau janda1, (c) Adat pakaian perempuan yaitu 60 real kalau janda 2, (d) Tempayan kapat (yang masih gadis), (e) Anding padang (seperangkat alat tidur), (f) Cincin penyewak (cincin yang polos), (g) Pesalin perempuan (calon istri), (h) Pesalin orang tua laki (mertua laki-laki, (i) Pesalin orang tua peremmpuan (mertua perempuan), (j) Tingkau uban (apabila nenek perempuan masih hidup), (k) Uang asap (sesuai dengan musyawarah kedua belah pihak)

\section{Pasal 15 Sangsi Adat}

Nikah/Kawin. Apabila poin pasal 14 huruf a sampai dengan $\mathrm{k}$ masih ada yang kurang dalam pemeriksa perempuan didampingi oleh tokoh adat maka menjadi hilang pihak mempelai laki-laki kecuali pihak perempuan mengikhlaskan barang tersebut.

\section{Pasal 16Adat Upacara}

Pernikahan/perkawinan. Adat 


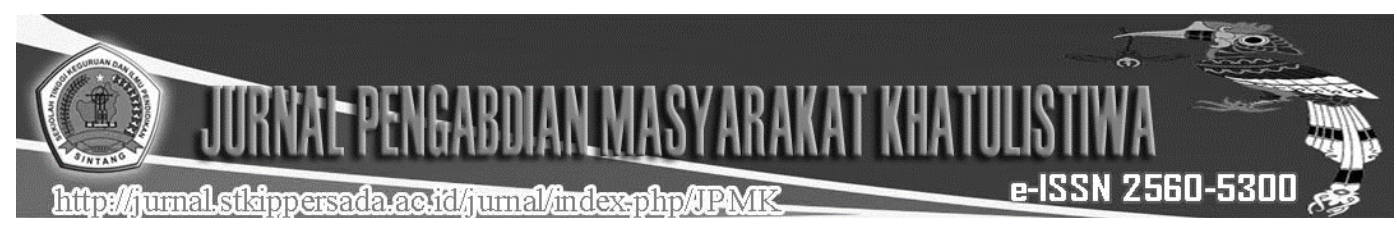

upacara pernikahan adalah kegiatan yang tidak mengikat dan disesuaikan dengan kemampuan masing-masing pihak yaitu sebagai berikut:

Bergantung/Kegiatan membenahi rumah tangga/menghiasi yang dikerjakan secara gotong-royong oleh seluruh keluarga.

Nyembelih/Kegiatan menyiapkan bahan-bahan yang akan dipakai pada acara selamatan dan dikerjakan gotongroyong oleh seluruh keluarga.

Mandi berias/Kegiatan membenahi calon pengantin dan sekaligus pengukuhandari kedua belah keluarga yang ditandaidengan memberi minum air putih dan tepung tawar pada pasangan pengantin. (4) Mandimandi/Merupakan acara penutup dari rangkaian kegiatan sekaligus membenahi barang-barang yang di pakai dalam kegiatan tersebut dan dikerjakan sacara gotong-royong. (5) Menaik/Setelah 3 hari/7 hari selesai acara pernikahan, suami mengajak istri mengenal rumah dan keluarga pihak suaminya lebih dekat lagi ditandai dengan mencelok tempayan kapal (tempayan beras) dengan harapan agar menantu tersebut tidak ragu-ragu lagi melaksanakan pekerjaan dirumah sang mertua.

Keluarga mencelok/Biasanya mengabil uang /cincin emas yang dihadiahkan oleh pihak mertua perempuan yang disimpan didalam tempayan beras sebagai tanda kasih sayangterhadap menantunya

\section{Pasal 17 Akad Nikah}

Akad nikah ini biasanya dilaksanakan pada acara mensurung atau tersendari tidak menjadi masalah, tetapi pelaksanaanya akad nikah tunduk pada peraturan perundang-undangan yang berlaku (kementerian agama).Pasal 18Mahar/Pemberian. Mempelai lakilaki pada saat akad nikah menyerahkan mahar/pemberian berupa uang atau barang kepada mempelai perempuan berdasarkan kesepakatan dengan calon pengantin perempuan (yang punya hak)

Pasal 19Penceraian/Rujuk

Penceraian/Penceraian antara suami dan istri adat tunduk kepada peraturan perundang-perundang yang berlaku/pengadilan agama, kecuali:Nikah Kampung (tanpa surat nikah) dan dibenarkana. oleh pengadilan tersebut andai kata si suami yang akan menceraikan istrinya oleh pengurus adat ditanya permasalahannya apa kesalahan istrinya sampai diceraikan,andai kata kesalahan istrinya tidak seberapa bisa memanfaatkan pengurus adat coba tinya etapi kalau tidak bisa didamaikan dengan cara apapun kesalahan istrinya itu hanya untuk alsan saja, timbale adat pemuang 1200 real.Harta benda termasuk juga rumah sebagai hak yang 


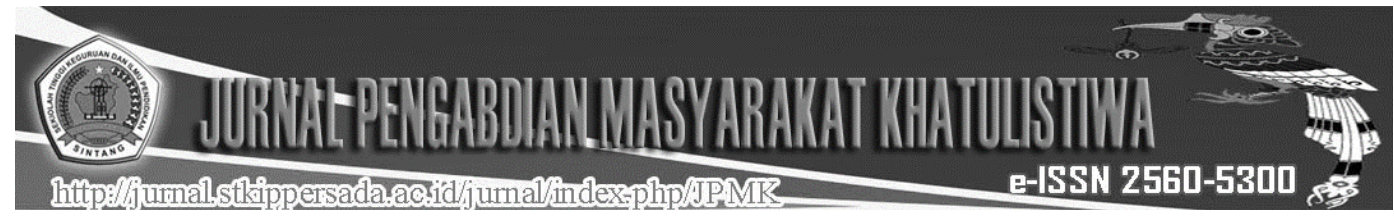

dibuang dan harus mengisi uang tidak sesuai dengan ketentuan agama, tenggung anak sesuai dengan perjanjian orang tua laki-laki maupun perempuan tidak boleh dibagi.

(2) Rujuk adat tunduk kepada peraturan perundang-undangan yang berlaku /pengadilan agama.

\section{Pasal 20 Kerangkat}

Kerangkat yaitu seorang laki-laki mempunyai istri lantas istrinya dirampas oleh laki-laki lain urusannya diserahkan kepada berwenang/pengadilan agama melalui kantor urusan agama (KUA) dan ternyata kedua boleh dikawin berlaku ketentuan adat sebagai berikut: (a) Adat kerangkat: 200 real/100 gram emas, (b) Kesupan orang tua: $20 \mathrm{real} / \mathrm{sesuai}$ dengan jabatan, (c) Kesuapan kampong: $100 \mathrm{real} / \mathrm{Rp} .10 .000,-$, dan (d) Kesuapan adat: $80 \mathrm{real} / \mathrm{Rp} .8 .000 .000,-$

\section{Pasal 21Keronggong}

Keronggong yaitu seorang laki-laki yang sudah beristri dirampas seseorang yang sudah punya istri juga, adat keronggong sama dengan kerangkat pasal 19 dari huruf a sampai dengan $\mathrm{d} x$ 2 = sesuai dengan harga 200 gram emas.

\section{Pasal 22Madu}

Jika laki-laki yang telah mempunyai istri ingin kawin lagi/kawin muda urusannya diserahkan pada yang berwenang/peradilan agama, melalui kantor urusan agama (KUA) setempat. Pasal 23 Taklik. Taklik adalah adat bergantung kepada peraturan perundang-undangan yang berlaku (kementerian agama).

\section{Pasal 24 Pelangkah Batang}

Apabila dua orang gadis bersaudara atau lebih kemudaian si adik dulu di pinang oleh orang, sedangkan kakaknya belum maka timbullah adat pelangkah batang untuk kakanya 10 real.

Pasal 25Pernikahan/Perkawinan Antara

Suku

Pernikahan / perkawinan antara suku adatnya menurut pihak perempuan.

BAB VADAT BERDUSAPasal 26Basa Berdusa. Apabila antara lakilaki dan perempuan yang bukan muhrim berada pada sesuatu tempat dan sudah mengarahkan pada perbuatan zinah akan dikenakan sangsi sebagai berikut: (a) Basa: 20 real senilai dengan Rp.200.000, (b) Kesuapan kampung: 80 real senilai dengan Rp.800.000,-, (c) Kesuapan orang tua: 20 real senilai dengan Rp.200.000,-

Pasal 27Basa Berbusa

Merajalela

Apabila antara laki-laki dan perempuan yang bukan muhrim pada sesuatu 
tempat dan sudah mengarahkan pada perbuatan zinah yang brsifat memmaksa sepihak (ancaman) maka dikenakan sangsi adat sebagai berikut: (a) Basa berdusa merajalela: 60 real senilai dengan Rp.600.000,- (b) Kesuapan kampung: 80 real senilai dengan Rp.800.000,- (c) Kesuapan orang tua: 20 real senilai dengan Rp.200.000, (d) Pelanggar adat: 80 real senilai dengan Rp.800.000,-

\section{Pasal Basa Biasa}

Pergaulan bebas : apabila antara lakilaki dan perempuan yang bukan uhrim berada ditempat yang menurigakan dan mengarahkan pada hal yang negatif akan diberikan sangsi adat sebagai berikut: (a) Basa: 20 real senilai dengan Rp.200.000,-, (b) Kesuapan kampung: 80 real senilai dengan Rp.800.000, (c) Kesuapan orang tua: 20 real senilai dengan Rp.200.000,- Keterangan : untuk kesuapan orang tua masih dinilai sikap orang tua yang bersangkutan terhadap anak.

\section{Pasal 29 Perzinahan}

Perzinahan adalah hubungan seks (persetubuhan antara laki-laki dan perempuan yang bukan suami istri dibagi dalam 3 kategori adat sebagai berikut: (1) Perzinahan antara pemuda dan pemudi (bujang dan dara) dikenakan sangsi adat sebagai berikut:

(a) Adat perzinahan: 60
real/Rp.600.000,- $\quad$ (b) Kesuapan kampung: 80 real/Rp.800.000,- (c) Kesuapan orang tua: 20 real Rp.200.000, (2) Perzinahan antara lakilaki dan perempuan yang sudah mempunyai suami istri dikenakan sangsi sebagai berikut: (a) Adat perizinan: 100/50 real/gram emmas Rp.21.000.000,- (b) Kesuapan kampung: 80 real/Rp.800.000,- (c) Kesuapan orang tua: 20 real/Rp.200.000,- (3) Perzinahan antara laki-laki dan perempuan yang sudah punya suami istri dengan jejaka dan gadis dikenakan sangsi sebagai berikut: (a) Adat perizinan: 100/50 real/gram emmas Rp.21.000.000,- (b) Kesuapan kampung: 80 real/Rp.800.000,- (c) Kesuapan orang tua: 20 real/Rp.200.000,-

\section{Pasal 30Ngampang}

Ngampang adalah suatu perbuatan cabul yang mengakibatkan seseorang hamil diluar nikah adatnya sebagai berikut: (a) Pelanggar adat: 80 real/Rp.800.000,- (b) Kesuapan kampung: 80 real/Rp.800.000,- (c) Kesuapan orangt tua : 20 real/Rp.200.000,- (d) Tanggung anak s/d 15 tahun ${ }^{2} p .54 .000 .000,-$ Apabila mereka berkeinginan untuk kawin maka dikenakan separuh adat dari point $\mathrm{a}$ dan $\mathrm{b}$

\section{BAB VI Kematian}




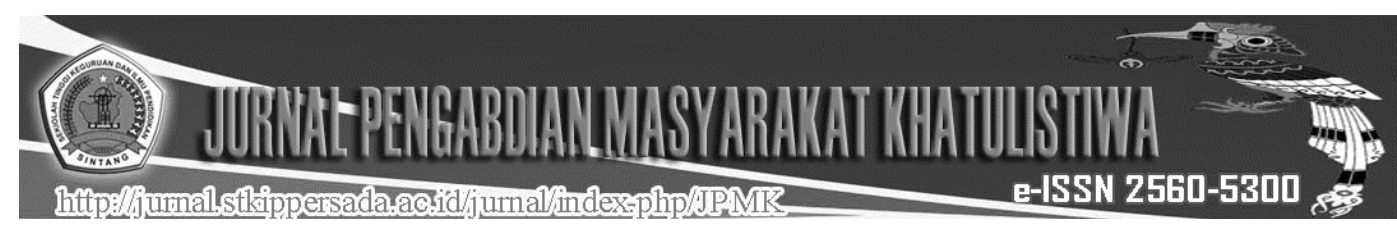

Kematian yang dimmaksud

menghilangkan nyawa seseorang

manusia dengan unsur sengaja/tidak

sengaja, dikenakan sangsi adat sebesar Rp.40.000.000,-

Pasal 31 unsur

Sengaja/Terencana. Kematian yang disebabkan unsur sengaja /terencana oleh seseorang kepada pihak lain dikenakan sangsi adat sebagai berikut : urusannya diserahkan kepada pihak berwenang (hukum positif). Pasal 32 Unsur Tidak Sengaja. Kematian yang disebabkan dengan unsur tidak sengaja oleh seseorang kepada pihak lain, maka dapat dikenakan sangsi adat apabila ada pelimpahan dari pihak yang berwenang/peerintah/camat sebagai berikut: (a) Membayar santunan (pasti) sebesar Rp.35.000.000,- (b) Membayar biaya pemakaman sesuai dengan kesepakatan kedua belah pihak.

\section{Pasal 33Cacat Badan/Lumpuh}

Apabila terjadi kecelakaan yang mengakibatkan cacat/lumpuh anggota badan seoarang maka akan dikenakan sangsi sebagai berikut: (a) Membayar setengah santunan sebesar Rp.17.500.000,- (b) Cacat ringan (ruas jari/kaki) dihitung secara persentase dari harga emas

\section{Pasal 34Sebab-sebab Lain}

Kematian oleh sebab lain seperti kena penyakit (kuman) atau oleh karena

melahirkan yang atas keinginan bersama untuk mendapatkan keturunan dari lain-lain sangsi adat adalah sebagai berikut: (a) Keluarga (ahli waris) bertanggung jawab mengurus pemakamanya. (b) Mendo'akan mayat (jenazah) tersebut agar diterima di sisi Tuhan Yang Maha Esa.

BAB VII PERKELAHIAN/ PERTIKAAN/SENGKETAPasal

35Perkelahian/pertikaan/sengketa adalah suatu perbuatan yang dianggap sudah meresahkan tidak aman atau terancam pihak lain sangsi adatnya sebagai berikut:(a)Kedua belah pihak membayar adat pemamar kampyung :80 real/Rp.800.000,- untuk setiap orang yang terlibat secara jelas.(b)Kepada orang yang ternyata bersalah dikenakan adat sesuai dengan kesalahan(c)Point a dan b dapat dikenakan adat apabila belumm menjurus pada hukum positif.

\section{BAB VIII HUKUM}

\section{KELUARGA}

Pasal 36Hukum keluarga menurut adat sebagai berikut: (a) Garis lurus kebawah (b) Keluarga pihak laki-laki dari pihak bapak lebih kuat dari pihak perempuan atau ibu. (c) Anak laki-laki lebih kuat dari anak perempuan dan keluarga /saudara laki-laki dari pihak bapak

BAB IXHUKUM BENDA 
Hukum benda adalah seperti tanah perkuburan/tempat keramat sangsi adat adalah sebagai berikut: (1) Tindakan semena-mena dikenanakan sangsi adat sebagai berikut: (a) Kesuapan merajalela (ket.tidak boleh diganggu gugat) (b) Membayar ganti rugi atas segala kerugian. (2) Tindakan yang tidak semena-mena atasa dasar musyawarah/mufakat adatnya adalah sebagai berikut: membayar santunan ganti rugi atas dasar musyawarah/mufakat.

\section{BAB XWARIS ADAT}

Waris adat adalah harta benda yang dimmiliki secara turun temunurun berdasarkan garis lurus kebawah atau menurut agama/usul fikih,sangsinya adalah sebagai berikut: (a) Apabila seseorang menerima warisan tidak berdasarkan petunjuk agama islam maka warisan tersebut dapat dibatalkan oleh pengurus adat. (b) Si penerima yang tidak sah dikenakan, ketika pelanggar (contoh) kebun karet/lainlain yang diterima si A selama 1 tahun yang lalu setelah diteliti yang berhak menerima adalah si B maka si A harus mengebalikan seluruh kegiatan kerugian yang di derita si B.

\section{BAB XIWASIAT}

Wasiat adat/uanah, dibenarkan apabila sebagai berikut: (1) Ada persetujuan ahli waris yang sah menurut agama. (2)
Diketahui dua orang saksi yang sah sangsi adat sebagai berikut: (a) Apabila bertentangan dengan hukum agama maka wasiat tersebut dinyatakan batal. (b) Apabila wasiat adat tersebut tidak memenuhi ketentuan wasiat diatas, maka wasiat tersebut dinyatakan batal. (3) Membayar denda pelanggaran hukum agama oleh pengurus adat dikenakan sangsi adat sebesar : 80 real/ Rp. 800.000,-

\section{BAB XII HIBAH ADAT}

Hibah adalah pemberian barang/benda kepada seseorang secara sah apabila: (a) Harus ada persetujuan pihak yang memiliki barang/benda yang dihibahkan dan tanda tangani dua orang saksi yang sah. (b) Bagi yang tidak memenuhi ketentuan diatas, maka hibah tersebut dinyata batal dan membayar urusan pelanggaran sebesar 80 real/Rp. $800.00,-$.

\section{PASAL XII GADAI} SECARA ADAT Pasal 41 Gadai adalah jual beli bersifat mengikat atau bersyarat sebagai berikut: (a) Harus ada persetujuan 2 belah pink (perjanjian) yang memiliki batas waktu tertentu (jatuh tempo). (b) Apabila batas waktu (jatuh tempo) telah habis maka si penggadai harus mengambil barang/benda tersebut berdasarkan perjanjian. (c) Apabila tidak diambil pada tanggal jatuh tempo, maka 


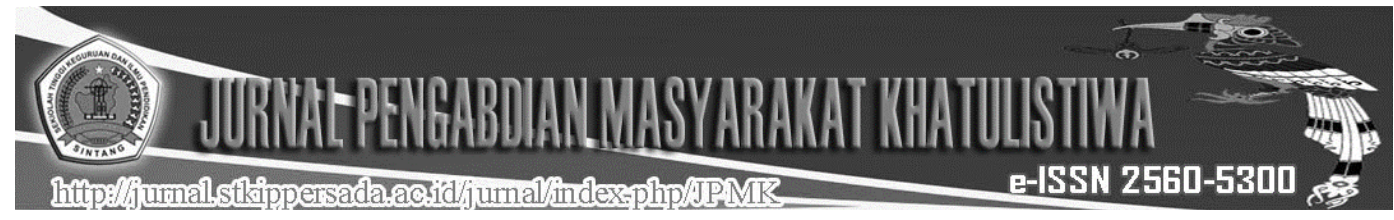

barang/benda menjadi milik si pembeki atau si penerima gadai, (d) Perjanjian boleh diperbaharui kemabali berdasarkan musyawarah kedua belah pihak.

BAB XIV SENGKETA TANAH. Pasal 42 Sengketa tanah adalah perselisihan antara kedua pemilik tentang status dan asal usul tanah tersebut, maka akan diadakan pemeriksaan sebagai berikut: (a) Penelitian asal usul tanah/kepemilikan, (b) Adanya keterangan dari saksi-saksi yang dianggap sah menurut adat Sangsi adat adalah sebagai berikut: (a) Mengembalikan hak milik tanah kepada yang berhak, dan (b) Membatalkan seluruh perjanjian yang tidak sah.

\section{BAB XV HAK ULAYAT}

Pasal 43 Hak ulayat adalah tanah kebun (tanam tumbuh) yang dimiliki secara turun temurun an diakui oleh penduduk setempat menjadi hak milik yang sah baik oleh perorangan maupun oleh kelompok sangsi adat sebagai berikut: (1) Tanah /kebun (tanam kebun) yang tidak jelas bukti kepemilikannya menurut adat akan dikembalikan kepada ysng berhak menerimanya/negara. (2) Bagi yang terbukti mengambil hak milik orang lain secara sah dikenakan sangsi adat sebagai berikut: (a) Membayar adat basa sebesar 30 real /
Rp.300.000, (b) Membayar ganti rugi yang dirusak kalau ada

\section{BAB XVI ADAT BASA}

Pasal 44 Adat basa adalah segala tindak-tindak yang sifatnya memalukan/melecehkan orang lain, sangsi adat adalah sebagai berikut: (1) Camat/temenggung kordinator (stingkatnya): 100 real dan (2) Kepala Desa/Adat (setingkatnya): 80 real, (3) Aparat Desa/Dusun (Setingkatnya) :60 real, (4) Ketua RT (Setingkatnya): 40 real (5) Masyarakat biasa: 20 real

\section{BAB XVII KESUAPAN}

Pasal 45 Kesuapan adalah ucapan dan yang memalukan orang, sangsinya adalah sebagai berikut:

Camat/Temengung kordinator (setingkatnya): 100 real dan (2) Kepala Desa/adat (setingkatnya): 80 real

BAB XVII NUBA ADAT Pasal 46 Nuba adalah kegiatan turun temurun yang didasari keyakinan nenek moyang untuk menghilangkan semua sial-sial dan bibit penyakit yang datang dari air maupun dari darat. Adapun aturan adatnya sebagai berikut: (1) Nuba adat satu kali setahun (2) Tidak membenarkan jenis tuba seperti bahan kimia (dilarang) yang diperbolehkan adalah tuba alam, tuba buah dan tuba akar, sangsi adat adalah sebagai berikut: (a) Membayar pelanggar adat: 80 real /Rp.800.000,- (b) Kesupan kepala adat: 
80 real/ Rp.800.000,- (c) Yang menggunakan bahan kimia didenda $\mathrm{Rp}$. 800.000,- (d) Tidak mau didenda /serah ke hukum positif

\section{BAB XIX PATI POHON BUAH-}

BUAHAN. Pohon buah-buahan yang sengaja ditebang/dirusak sengaja atau tidak sengaja, sangsi patinya adalah sebagai berikut: (1) Tengkawang dilihat besar kecil pohon dan ukurannya (a) Ukuran pertampangan/garis tengah 1 meter: 40 real (b) Ukuran pertampangan/garis tengah $80 \mathrm{~cm}: 30$ real, (c) Ukuran pertampangan/garis tengah $50 \mathrm{~cm}$ : 35 real (d) Ukuran pertampangan/garis tengah $40 \mathrm{~cm}: 30$ real (e) Ukuran pertampangan/garis tengah $40 \mathrm{~cm}$ kebawah: 20 real (2) Durian dan sejenisnya sama dengan poin diatas: 35 real (3) Cempedak: 20 real (4) Langsat: 20 real (5) Leban: 20 real (7) Kemayau: 20 real (9) Nangka: 20 real (10) Entawak: 20 real (11) Rambai: 40 real (12) Mawang: 40 real (13) Kemantan: 40 real 14) Asam pelam: 40 real (15) Mangga: 40 real (16) Keranjik: 40 real (17) Belimbing: 20 real (18) Rotan/rumpun: 20 real (19) Paoh: 40 real (20) Enau: 40 real (21) Rambutan/kelotok: 40 real (22) Rambutan biasa: 20 real (23) Petai/jengkol: 60 real (24) Kepuak: 20 real (25) Karet Dewasa: 5 real,
Remaja: 2.5 real, Bukit sesuai harga saat itu

\section{BAB XX HEWAN PELIHARAAN}

Pasal 48 (1) Sapi (a) Api harus dikandang dan diikat, mengikat sapi tersebut dilarang di lapangan bola kaki, lapangan poli lapangan sekolah, lapangan kantor, lapangan/perkarangan masjid, gereja, kapel dan perkarangan milik orang lain maupun dimakam serta perkebunan milik orang lain, apa sebab dilarang : karena menganggu lingkungan hidup orang lain dan pencemaran, juga merusak tanam tumbuh, inilah yang sering terjadi. (2) Kambing seperti huruf A diatas Sangsi adat: (a) Membayar pelangkah adat 80 real (b) Andai kata ada tanam tumbuh yang dimakam/rusak pemilik sapi menggantinya sesuai dengan kerusakan. (3) Anjing untuk suku melayu yang mayoritasnya agama Islam dilarang memeliharannya, hukumnya haram/adat pemali besar, tidak ada hukum adat semuanya resiko pemmilik pemelihara anjing tersebut.

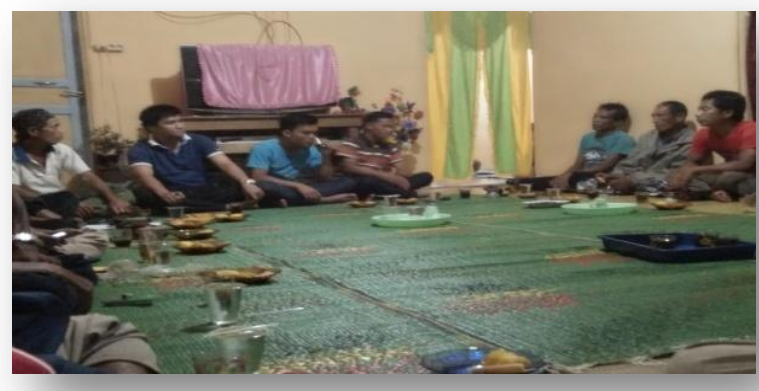


Andai kata anjing tertabrak kendaraan roda empat/roda dua/mobil/motor mati tidak ada ganti rugi. Andai kata tabrakan tersebut mengakibatkan kendaraan rusak dan yang memmbawa kendaraan itu cacat ringan/berat atau mengakibatkan kematian resikonya ditanggung pemilik anjing tersebut.

Adat kecampur. Adat kecampuran yang dimmaksud adalah seseorang yang bukan agama isalam yang membawa babi atau memasaknya dirumah seorang Islam sangsi adatnya 60 real/Rp.600.000,-tidak ada keras sengkelan. Seseorang yang bukan agama Islam membawa/menjual barang binatang yang halal seperti sapi, rusak, kijang dan sebagainya,dikatakannya sudah disembelih orang Islam sedang orang islam membeli dan telah dimakan setelah itu ada berita dari orang lain bahwa binatang itu tidak disembelih, sangsi adatnya $140 \mathrm{real} / \mathrm{Rp} 14.000 .000,-$ adat tersebut kembali/diserahkan kepada pengurus masjid untuk pembangunan. Pemilik sikin seseorang yang masuk agama Islam kemudian kembali ke agama lain/mualaf sangsi adatnya 60 real/Rp.600.000,-

\section{BAB XXI WEWENANG ADAT}

Pasal 49 Ketentuan wewenang adat sejak tanggal 07 mei 2014 adalah sebagai berikut: Kepala Desa/ Kepala
Dusun/ Ketua RT hanya mengurus halhal yang bersifat damai atau perdamaian 20 real, ke atas adalah urusan Kepala Adat, apabila kepala adat berhalangan maka membuat surat perlimpahan kepada kepala desa dengan tembusan kepada Camat dalam waktu ditentukan.

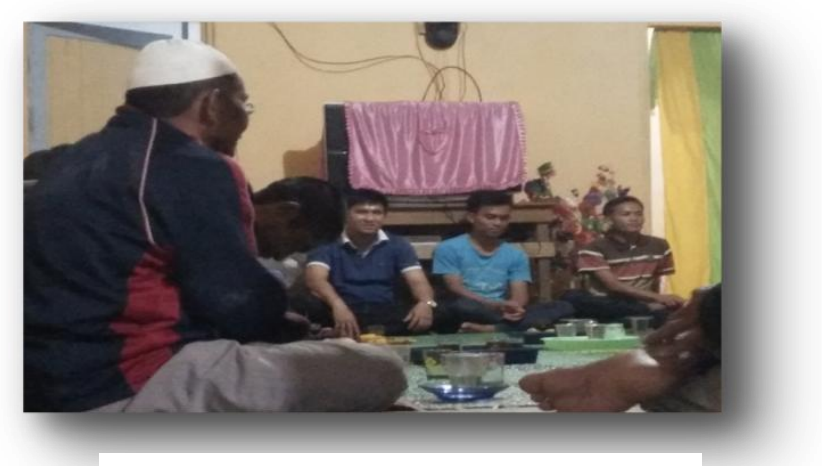

Gambar 1. Rapat Peninjauan Adat

\section{Pembahasan}

C. Dewi Wulansari (2012: 25) mengatakan bahwa hukum adat adalah istilah untuk menunjukkan hukum yang tidak dikodifikasikan dalam kelangan orang Indonesia asli dan kalangan Timur Asing (Tionghoa, Arab dll). Hukum adat senantiasa tumbuh dari suatu kebutuhan hidup yang nyata, cara hidup dan pandangan hidup yang keseluruhannya merupakan kebudayaan masyarakat tempat hukum adat itu berlaku.Hukum pidana adat secara umum berisi mengenai aturan-aturan 
hukum yang kebanyakan bersifat tidak tertulis namun memiliki akibat hukum bagi siapapun yang melanggar hukum tersebut, didalam wilayah hukum adat tersebut berlaku.

Hukum adat masih memiliki pengaruh yang kuat dalam lingkungan Masyarakat Hukum Adat Melayu Melingkat Ingar Silat. Hukum adat yang masih tetap dipegang teguh oleh masyarakat Melayu Melingkat sampai saat ini di antaranya hukum adat menghamili perempuan di luar menikah atau kampang, berzinah, mencuri, membunuh, dan bertengkar. Proses penyusunan dilakukan dengan cara persiapan, pelaksanaan kegiatan program, manajemen organisasi masyarakat, partisipasi mitra, evaluasi program, dan laporan program.

\section{Simpulan}

Kegiatan PkM dimulai denganpersiapan, pelaksanaan kegiatan program, manajemen organisasi masyarakat, partisipasi mitra, evaluasi program, laporan programterhadap hukum adat Melayu Desa Melingkat Inggar Silat Kecamatan Kayan Hilir Kabupaten Sintang. Hukum adat diantaranya Adat Pemali, Hukum Nikah/Perkawinan, Adat Berdusa, Perkelahian/Pertikaian/Sengketa,

Hukum Keluarga, Waris Adat, Wasiat, Hibah Adat, Gadai Secara Adat,
Sengketa Tanah, Hak Ulayat, Adat Biasa, Kesupan, Nuba Adat, Dan Hewan Peliharaan. Adat Istiadat adalah kebiasaan perilaku kehidupan manusia secara turun temurun yang diakui kebenarannya dan dijunjung tinggi oleh masyarakat suku Melayu yang mayoritasnya umat yang beragama Islam, dan bersamaan dengan hukum syarat berazaskan Al-Qur'an dan Hadisthadistnya dalam lingkungan Kecamatan Kaya Hilir.

\section{Saran}

Berdasarakan hasil PkM di Desa Melingkat maka beberapa saran sebagai berikut.(1) Adanya kerjasama lanjutan dalam hal proses penyusunan hukum adat Melayu desa Melingkat Kecamatan Kayan Hilir Kabupaten Sintang, dan (2) Hukum adat harus ditaati dan dijunjung tinggi oleh semua warga Desa Melingkat agar tercipta rasa keadilan dan rasa aman dan nyaman

\section{Daftar Rujukan}

A. Muin Ikram. 2007. Adat Istiadat Perkawinan Melayu Sambas. Naskah. Sambas: MABM Sambas.

Muhammad, Bushar. 2013.Pokok Pokok Hukum Adat. Jakarta:Balai Pustaka.

Purnamasari, Irna Devita. 2014. Hukum Waris. Bandung: PT Mizan Pustaka. 
J. Purba, dkk. 2009. Sejarah dan Perkembangan Kebudayaan Melayu di Kalimantan Barat. Jakarta: Dit Nilai Sejarah, Depdikbud RI.

Wulandari, C. Dewi.2012.Hukum Adat Indonesia Suatu Pengantar., Bandung: Refika Aditama. 